\title{
International Journal of Education and Management
} Engineering

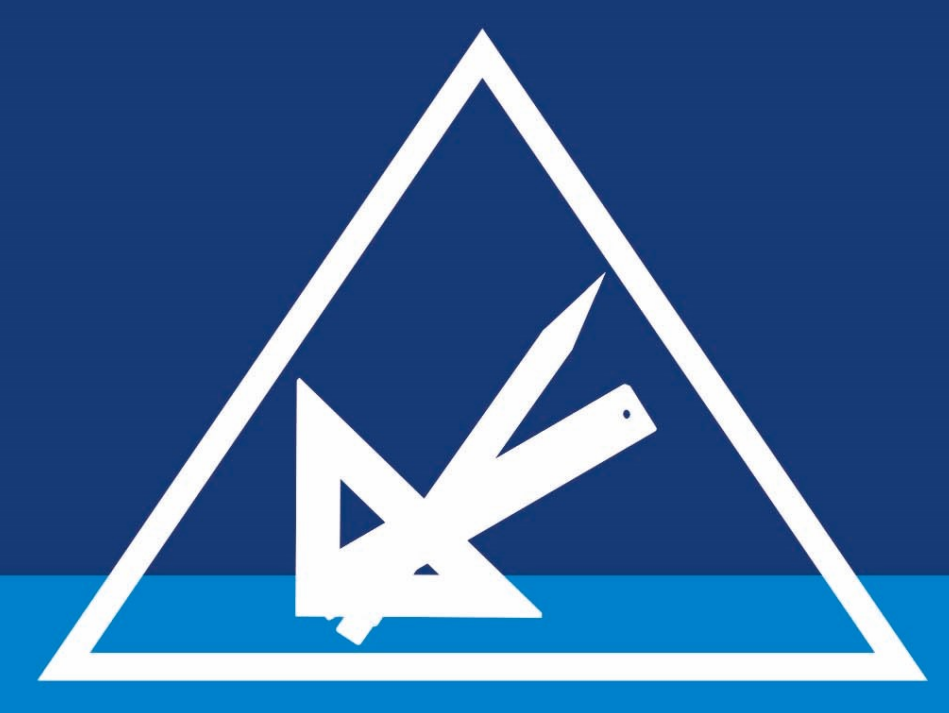

IEEME KoI. 10 Http:// www.mecs-press .org Vol.10 No.4 August 2020 


\section{International Journal of Education and Management Engineering (IJEME)}

ISSN: 2305-3623(Print), ISSN: 2305-8463(Online)

Volume 10, Number 4, August 2020

\section{Contents}

\section{REGULAR PAPERS}

Classification of Coronary Artery Disease Using Different Machine Learning Algorithms

Bahar Nazl, Yasemin Gültepe, Hayriye Altural

A Roadmap Towards Big Data Opportunities, Emerging Issues and Hadoop as a Solution

Rida Qayyum

Fuzzy K-Nearest Neighbour Model for Choice of Career Path for Upper Basic School Students

Awoyelu I.O., Oguntoyinbo E. O., Awoyelu T. M.

An Internet of Thing based Agribot (IOT- Agribot) for Precision Agriculture and Farm Monitoring

Kakelli Anil Kumar, Aju. D.

Evaluation Study of Software Quality Management (SQM) and Quantitative Process 40

Management (QPM) in Pakistan Software Houses

Muhammad Haroon 